\title{
SPATIO-TEMPORAL RESPONSE OF SEDIMENTARY DIATOMS TO WATER LEVEL IN A SHALLOW LAKE
}

\author{
GUO, T. ${ }^{1,2^{*}}-\mathrm{CHEN}, \mathrm{H}^{1}{ }^{1}$ \\ ${ }^{1}$ State Key Laboratory of Water Environment Simulation, School of Environment, Beijing \\ Normal University, 100875 Beijing, China \\ ${ }^{2}$ Biodiversity and Ecological Modelling and DCPS, Institute of Biology, Freie Universität \\ Berlin, 14195 Berlin, Germany \\ (phone: +49(0)30-83853155; fax: +49(0)30-83853155) \\ *Corresponding author \\ e-mail: guo.tong@fu-berlin.de \\ (Received 24 $4^{\text {th }}$ Aug 2015; accepted $23^{\text {rd }}$ Jan 2016)
}

\begin{abstract}
In recent years, human activities have resulted in variations of hydraulic conditions in shallow lakes, thereby affecting interactions between environmental variables and aquatic plants. This feedback of plants on environmental changes is largely recorded in lake sediments. In this study we collected surface sediments in different seasons and a sediment core from a shallow lake Baiyangdian. We investigated the seasonal effects of water level and six physicochemical variables in surface sediments, as well as their impacts on the distribution of diatom assemblages. Therein the response of diatom assemblages to water level and the spatio-temporal effects of water level are highly emphasized. Results indicate that water level significantly changes between seasons, however there is no significant seasonal effects for the composition of grain size. The lake productivity increases with the vigorous growth of aquatic plants. Water level largely determines the distribution of diatom assemblages in surface sediments and the sediment core. Spatial isolation causes the difference between the habitats and alters the relation between water level and diatom taxa. Human activities also affect the relevance of water level with diatom assemblage. The results can provide the helpful information for the local water resource management.
\end{abstract}

Keywords: lake sediment; seasonal effects; abiotic and biotic factors; human activities

\section{Introduction}

Lake sediments can be seemed as a key sensor for assessing environmental changes and the fitness of lacustrine ecosystem (Battarbee, 2000). Sediments record variations of biotic factors and the impact of anthropogenic activities on a lake system within a historical period (Velghe et al., 2012). Most of researches have focused on the relation between the biotic factors and environmental changes in the body of water in shallow lakes (Habib et al., 1997; Phiri et al., 2007; Xie et al., 2013), whereas this relation was generally neglected in the sediments. Interactions between surface sediments and the body of water are largely dependent on the flow intensity and temporal fluctuations of water level in shallow lakes. Further variations of the lake underlying surface are closely related to fluctuations of water level. Varying water levels in shallow lakes alter the abundance and the diversity of aquatic plants, especially the phytoplankton community (Shinneman et al., 2010, Wang et al., 2012). Diatoms, as a member of phytoplankton, can be seemed as a reliable indicator to study the relation between the biotic factors in lake sediments and environmental changes (Moos et al., 2005).

Investigating the distribution of diatoms in surface sediments and its relation with physiochemical elements reflects the response of the biotic factors to environmental changes in a spatial scale. Examining the distribution of diatom communities found in 
surface sediments can improve our knowledge of variations in lake productivity (Facca et al., 2005). Spatial heterogeneity should be accounted for in shallow lakes given the difference of microhabitats and diatom assemblages in different lake areas. Koren and Klein (2000) found that surface sediments can be used to assess the spatial distribution of a biotic group in an open lake better than in a closed lake, by calculating the sedimentation rate. The seasonal measurements of indicative elements deposited in surface sediments can lead to an in-depth understanding of anthropogenic effects on the body of water in shallow lakes (Alagarsamy, 2006). The temporal scale of aquatic plants' response to environmental changes could be realized via the investigation of a sediment core. Current studies have put more emphasis upon one sediment core collected from a lake and the reconstruction of environmental variables, ignoring the spatio-temporal distribution of the variables and its effect on the composition of aquatic plants (Witkowski et al., 2009; Liu et al., 2012). Sediment cores are sometimes unreliable when determining the relationships between physiochemical variables and diatom assemblages since compaction, mineralization, and precipitation can weaken their correlation. In contrast, the concentrations of variables are relatively high but temporally dynamic regarding the surface sediments. Water level remains relatively stable over a short period. Using reconstructed and monitoring water levels to analyze the spatio-temporal response of diatom assemblages to environmental changes can help us to understand the spatio-temporal complexity of a lake, and further this might remove doubts that diatoms with different attributes can be found in one field (Weilhoefer and Pan, 2005). Variations of the freshwater diatom assemblage have shown to be closely linked to fluctuations of lake levels (Kingsbury et al., 2012; Leeben et al., 2013). Mean annual water level was a decisive variable affecting the distribution of diatoms in Lake Ossa. However, seasonal distributions of diatom assemblages are less related to water-level fluctuation (Nguetsop et al., 2010). In addition, Showing the seasonal effects of water-level fluctuation on the surface sediments is meaningless in case the lake sedimentation rate is low $(<0.1 \mathrm{~cm} / \mathrm{y})($ Tammeorg et al., 2013). Environmental variables indirectly linked to water level similarly affect the diatoms composition. Grain size and wind intensity determined the spatial distribution of diatom assemblages in surface sediments of the shallow lake Peipsi sensu stricto (Puusepp and Punning, 2011). Water quality is an assignable indicator affecting the response of diatoms to water level with respect to some shallow lakes, e.g. in Lake Vortsjarv, the abundance of planktonic diatoms had a significantly positive relation with water level before the 1960s, while this relation was weakened by the eutrophication after the 1960s (Heinsalu et al., 2008).

In this study, we concentrate on the corresponding response of diatom assemblages to water level based on the investigation of surface and core sediments. The studied shallow lake Baiyangdian experienced variations of water levels after the 1950s, since hydraulic projects have been constructed on the upper reach of the lake, which significantly affected hydrological conditions of the lake. Therefore the very surface sediments can be seemed as a product of human disturbance and the sediment core is a useful tool to provide the historical information of the lake. Hereby human disturbance is defined as human activities that interfere with the body of water and then indirectly interact on surface sediments, e.g. variations of water flow and water level due to the construction of hydrological projects, but do not indicate the direct disturbance on the surface sediments, e.g. excavation or pouring external materials. We address the following two points in our study: (1) seasonal effects of the surface sediments and water level (2) spatio-temporal response of diatom assemblages to water level and the effect of human 
activities on this response. The results can provide the useful information for regional water resource management and the protection of aquatic plants.

\section{Materials and Methods}

\section{Study area and sampling sites}

Baiyangdian is the largest freshwater shallow lake located in the north of China (Fig. 1), covering a total area of $366 \mathrm{~km} 2$. The lake has a large area of water and a nexus of water channels. These water channels are well connected with no human architecture in between. The body of water is weakly alkaline. An investigation of water quality during the period of June 2009 - April 2010 indicated that mean total phosphorus was 0.14 $\mathrm{mg} / \mathrm{l}$ and mean total nitrogen was $4.29 \mathrm{mg} / \mathrm{l}$ (Zhang et al., 2013). Baiyangdian is located in a warm temperate zone; the regional climate pattern typically displays a strong seasonality with arid windy springs, hot rainy summers, and cold dry winters. The mean annual temperature ranges from $7.3{ }^{\circ} \mathrm{C}$ to $12.7{ }^{\circ} \mathrm{C}$. Annual rainfall fluctuates from $350 \mathrm{~mm}$ to $750 \mathrm{~mm}$ (Zhang et al., 2013). Water table in the western area is generally higher than that in the eastern area. Water level seems to be a reliable indicator of reflecting hydraulic conditions of the lake. Water level ranges from $6 \mathrm{~m}$ to $9 \mathrm{~m}$ based on the record of chorography. Lake Baiyangdian is classified as a natural wetland that has 39 types of aquatic plants, among which Ceratophyllum demersum, a submerged plant, and Phragmites australis, an emergent plant, account for a considerable proportion of the aquatic plants. Severe droughts led to extremely low water levels and heavily destroyed the habitat of the aquatic plants at the beginning of the 1980s.

The sampling of sediments was implemented in November 2009, as well as in January, March, and July 2010. Eight sampling sites were selected to investigate the spatial characteristics of surface sediments (from north to south: SCD, WJZ, YZZ, ZLZ, LWD, QT, DTZ and CPT). It is time consuming to perform a biological analysis of excessive sampling points whereas few sampling points may not stand for the features of a lacustrine system (Weilhoefer and Pan, 2006). We collected surface sediments and four short sediment cores (core length $=20 \mathrm{~cm}$ ) in the first sampling, in order to determine an ideal place to obtain a long sediment core. One site CPT was found without laminated sediments, implying that physical mixing and bioturbation were relatively weak in the area. We collected the sediment core (core length $=80 \mathrm{~cm}$ ) and surface sediments representing different seasons in the sequential samplings. Unfortunately, we did not collect the surface sediments representative of the season autumn. The sediment core was collected with the BEEKER sediment corer at a water depth of $1.4 \mathrm{~m}$ in January. The sediment core was segmented at $2 \mathrm{~cm}$ interval and separated into 40 layers. The dating results of the sediment core have been introduced in the study of Guo et al. (2012). Surface sediments were collected elaborately to reflect seasonal variations of sediments. Surface sediments were taken repeatedly via a Peterson bottom grab, and passed through a $1 \mathrm{~mm}$ filter screen with the washing distilled water into a container, in order to remove larger extraneous matters. When filtered grains completely deposited in the bottom of the container, filtered waters in the upper layer were saved in glass bottles and the sediment grains were saved in sealed bags, and then were transferred to a refrigerator with a temperature of $-4{ }^{\circ} \mathrm{C}$. Two replicate samples in each sampling site were collected in an area of $5 \mathrm{~m} * 5 \mathrm{~m}$ to guarantee the samples of surface sediments not being directly disturbed by human activities. 


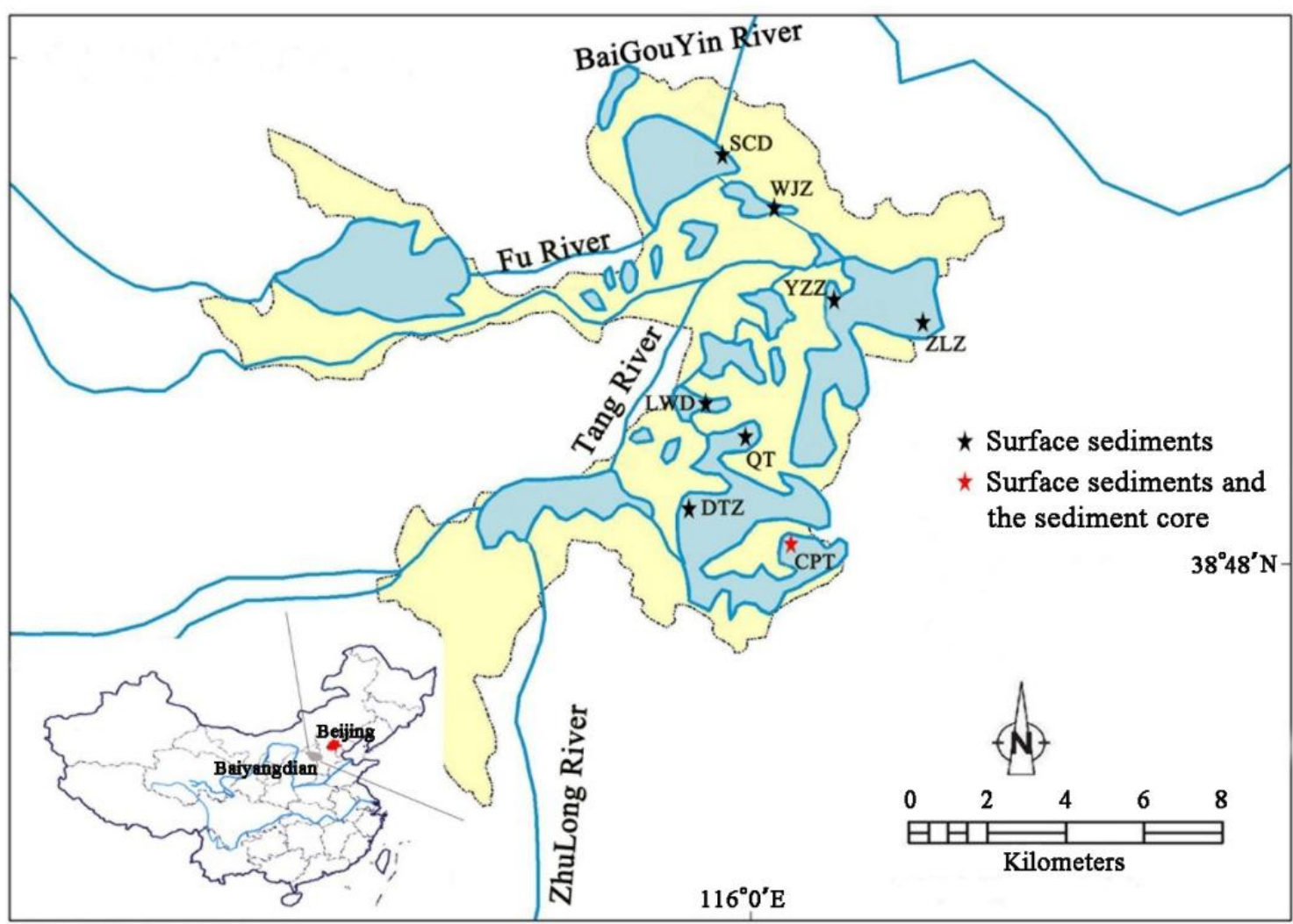

Figure 1. Location of study area and distribution of surface sediments and the sediment core. Yellow patches denote the land; blue patches denote the body of water; blue lines denote water channels.

\section{Measurement of sediment properties}

Environmental elements such as total organic carbon (TOC), the ratio of organic carbon to nitrogen $(\mathrm{C} / \mathrm{N})$, conductivity, $\mathrm{pH}$, available phosphorus (AP), and grain size were selected to investigate the property of surface sediments in spring and summer. In winter, the frozen surface sediments were not easy to filter and the amount of obtained samples was limited. Two variables, namely, loss of ignition (LOI) and grain size, were measured to assess the lake productivity and hydraulic conditions in this season. The distribution of grain size is typically used to determine the intensity and turnover rate of water flow. TOC and LOI can demonstrate the accumulation rate of organic matters. $\mathrm{C} / \mathrm{N}$ can differentiate the source of sedimentary materials. Conductivity and $\mathrm{pH}$ reflect the physiochemical environment of sedimentation. The abundance of phytoplankton may affect the concentration of AP.

We measured the initial wet weight of the surface sediments and dried these samples to determine the water content. TOC was measured using a High TOC-II analyser after a pre-treatment of $10 \%$ HCI on $0.5 \mathrm{~g}$ dry sediments (Huang et al., 2004). Total organic nitrogen $(\mathrm{TON})$ was determined by subtracting total inorganic nitrogen (TIN) from total nitrogen (TN) (Keeney et al., 1970), and then organic $\mathrm{C} / \mathrm{N}$ was calculated. $5 \mathrm{~g}$ dry samples were heated to $550{ }^{\circ} \mathrm{C}$ in a muffle furnace and were weighted to measure LOI. Conductivity and $\mathrm{pH}$ were measured with the 1:3 ratio of sediment-to-distilled water (Freeland et al., 1999). AP was measured in 100ml extractant with $0.2 \mathrm{~g}$ dry surface sediments after a preliminary digestion (DePinto et al., 
1981). A Winner 2008 laser particle size analyser was used to measure the grain size. The grain size was classified into clay $(<2 \mu \mathrm{m})$, silt $(<20 \mu \mathrm{m})$, and sand $(<$ $200 \mu \mathrm{m})$. Each environmental element was measured twice. Approximately $0.5 \mathrm{~g}$ dry samples of the surface sediments and each layer of the sediment core were taken for diatom identification. All sub-samples were placed in a $50 \mathrm{ml}$ tube with $\mathrm{H}_{2} \mathrm{O}_{2}$ and $\mathrm{HCl}$ digestion in a hot water bath at $80{ }^{\circ} \mathrm{C}$. We followed the procedure proposed by Moos et al. (2005). Thereafter all sub-samples were extracted using the floatation with heavy liquid $\mathrm{ZnBr}_{2}$, and then dispersed in $\mathrm{C}_{18} \mathrm{H}_{29} \mathrm{NaO}_{3} \mathrm{~S}$ solution to weaken the disturbance of the granule. Diatoms were mounted in synthetic resin mounting medium with a refractive index of 1.65 and were counted using a Nikon Ni50 microscope. More than 300 diatom frustules were enumerated per slide. Identification of diatoms followed the chrysophytax instruction in "The freshwater algae of China" (Qi, 1995; Qi, 2004; Shi, 2004; Li and Qi, 2010). The software C2 was applied to depict the distribution of diatoms (Juggins, 2003).

\section{Seasonal effects of surface sediments}

We used one-way ANOVA to show the seasonal effects of surface sediments. TOC and LOI of surface sediments had a significantly linear relation based on the study of Viguri et al. (2002). Therefore the value of LOI for winter samples can be converted into the value of TOC. One-way ANOVA of the variables grain size and TOC was conducted respectively with the MASS package of R. To reveal the spatial information and determine the principle variables in surface sediments, principle component analysis (PCA) was used on the surface sediments in spring and summer. This process was implemented with the pcaMethods package of R (Stacklies et al., 2007).

\section{Response of diatom assemblages to environmental variables}

The daily water levels in 2010 for different sampling sites were obtained from the local monitoring station. The seasonal water levels adopted the mean value of the daily water levels corresponding to each season. Historical water levels have been reconstructed using the indicative diatom species in the sediment core (Chen et al., 2013). According to the constructing time of the hydraulic projects on the upper reach of the lake and the dating results, the sediment core was separated into the relatively natural part (1827-1947 yr., lower layer: $80-14 \mathrm{~cm})$ and the humandisturbed part (1948 - 2008 yr., upper layer: $14-0 \mathrm{~cm})$ (Guo et al., 2012). The water levels fluctuated from $6.5 \mathrm{~m}$ to $9.5 \mathrm{~m}$ during the period of 180 years (Fig. Al). To emphasize the impact of human activities on the response of diatom assemblages in surface sediments to water levels, the diatoms of summer samples were identified since supplementary water flowed into the lake from the reservoir in the upper reach between spring and summer. Ordination methods were used to determine the effect of environmental factors on sedimentary diatom distribution (Yang et al., 2008). Detrended correspondence analysis (DCA) was used to estimate the gradient length of the first axis of the diatom distribution. Linear analysis is generally applied in case the first axis has a gradient length of less than 3(Ter Braak and Smilauer, 2002). Diatom species in one sample with the maximum abundance less than $3 \%$ were not accounted for, since rare species had a significant impact on the ordination analysis and then was downweighted. Margalef richness index and Pielou evenness index, jointly reflecting the diversity of diatom assemblage, were calculated for all 
the sediment samples (Mucha et al., 2003). Margalef richness index emphasizes the overall abundance of diatoms, whereas Pielou evenness index effectively indicates the distribution of diatom assemblages. We used the redundancy analysis (RDA) with respect to the response of diatom assemblages to environmental variables. Forward selection and Monte Carlo permutation tests were used to determine the key variables affecting the distribution of diatom assemblages. Constraining one variable to the first axis with treating other variables as covariables was implemented to assess the independent power of each key variable. All the environmental variables involved in the ordination analysis were $\log$-transformed $\left(\log _{10}(x+1)\right)$ to keep a similar scale. The ordination analysis was conducted with CANOCO version 4.5 (Ter Braak and Smilauer, 2002). To compare the results of the diatoms' response to the specific environmental variable in the spatial scale and in the temporal scale, we selected the diatom species simultaneously found in the surface sediments and the sediment core. Further we used grey correlation analysis to differentiate the response of individual diatom species to the specific environmental variable. The description of the method grey analysis can be found in Fu (2001). The species data and the environmental data have been dealt with a normalization in advance. We tested the sensitivity of the grey correlational coefficient $(\propto=0.3,0.4,0.5,0.6,0.7)$, and used the mean value and standard deviation (SD) to reflect the relation between diatom species and the specific environmental variable.

\section{Results}

\section{Seasonal effects of surface sediments}

The results show that sand fraction generally has a larger proportion in different seasons (Table 1). The percentage of clay ranges from $3.0 \%$ to $4.9 \%$, especially for sites YZZ and CPT with values more than $10 \%$ with respect to winter samples, whereas this percentage in most areas is zero in spring and summer. The sand content of the eastward sampling sites is higher than that of the westward sampling sites in the northern part, in contrast this trend is opposite in the southern part. Silt content at site ZLZ experiences a dramatic increase of $12.1 \%$ from spring to summer, since this site is located near a water channel connecting to the upper reach of the lake. The ratio of silt to sand varies not significantly across seasons ( $\mathrm{p}$ winter-spring $=$ $\left.0.221 ; \mathrm{p}_{\text {winter-summer }}=0.122 ; \mathrm{p}_{\text {spring-summer }}=0.345\right)$. The water levels seem higher in the middle section of the lake than that in the north and south sections. The water levels show significant seasonal difference ( $\mathrm{p}$ winter-spring $=0.017 * ; \mathrm{p}$ winter-summer $=$ $\left.0.0074 * * ; \mathrm{p}_{\text {spring-summer }}=0.011 *\right)$. The relation between the ratio of silt to sand and water level is closer in winter $\left(r^{2}=0.2\right)$, but is weaker in spring $\left(r^{2}=0.08\right)$ and summer $\left(r^{2}=0.0004\right)$. TOC varies significantly comparing the spring samples with the summer samples $(\mathrm{p}=0.00769 * *)$, while this variable in winter indicates no significant difference in comparison with that in spring $(\mathrm{p}=0.68)$ and in summer $(\mathrm{p}=$ $0.18)$. On the other hand, AP and C/N largely determine the property of surface sediments in spring, with the spindle values of 0.797 and 0.979 respectively. In contrast, AP and conductivity seem to be the key variables affecting the attribute of surface sediments in summer, with the spindle values of 0.904 and 0.930 respectively. The correlation between environmental variables in surface sediments slightly changes comparing the spring samples with the summer samples (Fig.2). Vigorous growing 
of algae stimulates a higher AP concentration at several sampling sites in summer than that in spring. Further the relation between $\mathrm{C} / \mathrm{N}$ and TOC is similar in these two seasons, implying that aquatic plants in the lake, rather than terrestrial plants around the lake, determine the source of organic matter in the surface sediments.

Table 1. Seasonal distribution of grain size, water level and TOC. Cl=Clay; $\mathrm{Si}=\mathrm{Silt} ; \mathrm{Sa}=$ Sand; $W L=$ Water Level

\begin{tabular}{cccccc|ccccc|ccccc}
\hline & \multicolumn{5}{c|}{ Winter } & \multicolumn{5}{c|}{ Spring } & \multicolumn{4}{c}{ Summer } \\
Site & $\begin{array}{c}\text { Cl } \\
\%\end{array}$ & $\begin{array}{c}\mathrm{Si} \\
\%\end{array}$ & $\begin{array}{c}\mathrm{Sa} \\
\%\end{array}$ & $\begin{array}{c}\text { WL } \\
\mathrm{m}\end{array}$ & $\begin{array}{c}\text { TOC } \\
\%\end{array}$ & $\begin{array}{c}\mathrm{Cl} \\
\%\end{array}$ & $\begin{array}{c}\mathrm{Si} \\
\%\end{array}$ & $\begin{array}{c}\mathrm{Sa} \\
\%\end{array}$ & $\begin{array}{c}\mathrm{WL} \\
\mathrm{m}\end{array}$ & $\begin{array}{c}\text { TOC } \\
\%\end{array}$ & $\begin{array}{c}\mathrm{Cl} \\
\%\end{array}$ & $\begin{array}{c}\mathrm{Si} \\
\%\end{array}$ & $\begin{array}{c}\mathrm{Sa} \\
\%\end{array}$ & $\begin{array}{c}\text { WL } \\
\mathrm{m}\end{array}$ & $\begin{array}{c}\text { TOC } \\
\%\end{array}$ \\
\hline CPT & 13.7 & 60.8 & 25.6 & 6.7 & 0.8 & 0 & 20.1 & 78.9 & 6.8 & 2.4 & 0.7 & 22.0 & 73.1 & 6.1 & 2.3 \\
DTZ & 4.6 & 35.1 & 60.3 & 7.7 & 1.4 & 0 & 17.2 & 78.2 & 6.7 & 4.8 & 3.0 & 24.5 & 68.3 & 6.8 & 5 \\
ZLZ & 3.9 & 47.8 & 48.3 & 8.6 & 2.2 & 0 & 8.6 & 85.0 & 8.2 & 3.9 & 0.4 & 20.7 & 72.4 & 7.6 & 4.6 \\
SCD & 4.9 & 36.7 & 58.4 & 7.1 & 1.7 & 0 & 9.0 & 89.8 & 7.1 & 4 & 0 & 13.8 & 78.7 & 6.7 & 3.8 \\
QT & 3.0 & 30.1 & 67.0 & 7.2 & 0.9 & 0.7 & 18.7 & 77.4 & 7.8 & 2.8 & 0 & 12.6 & 84.1 & 6.9 & 2.4 \\
LWD & 4.2 & 41.1 & 54.7 & 8.5 & 1.5 & 2.2 & 18.2 & 78.7 & 8.6 & 1.9 & 0 & 17.3 & 80.3 & 7.9 & 1.7 \\
YZZ & 12.9 & 58.5 & 28.6 & 6.8 & 2.0 & 1.2 & 23.0 & 74.8 & 6.9 & 2.1 & 2.4 & 26.5 & 68.9 & 7.1 & 3.3 \\
WJZ & 4.1 & 43.9 & 52.0 & 6.8 & 1.4 & 0 & 17.6 & 81.9 & 6.9 & 4.2 & 0 & 17.0 & 80.1 & 6.2 & 3.5 \\
\hline
\end{tabular}
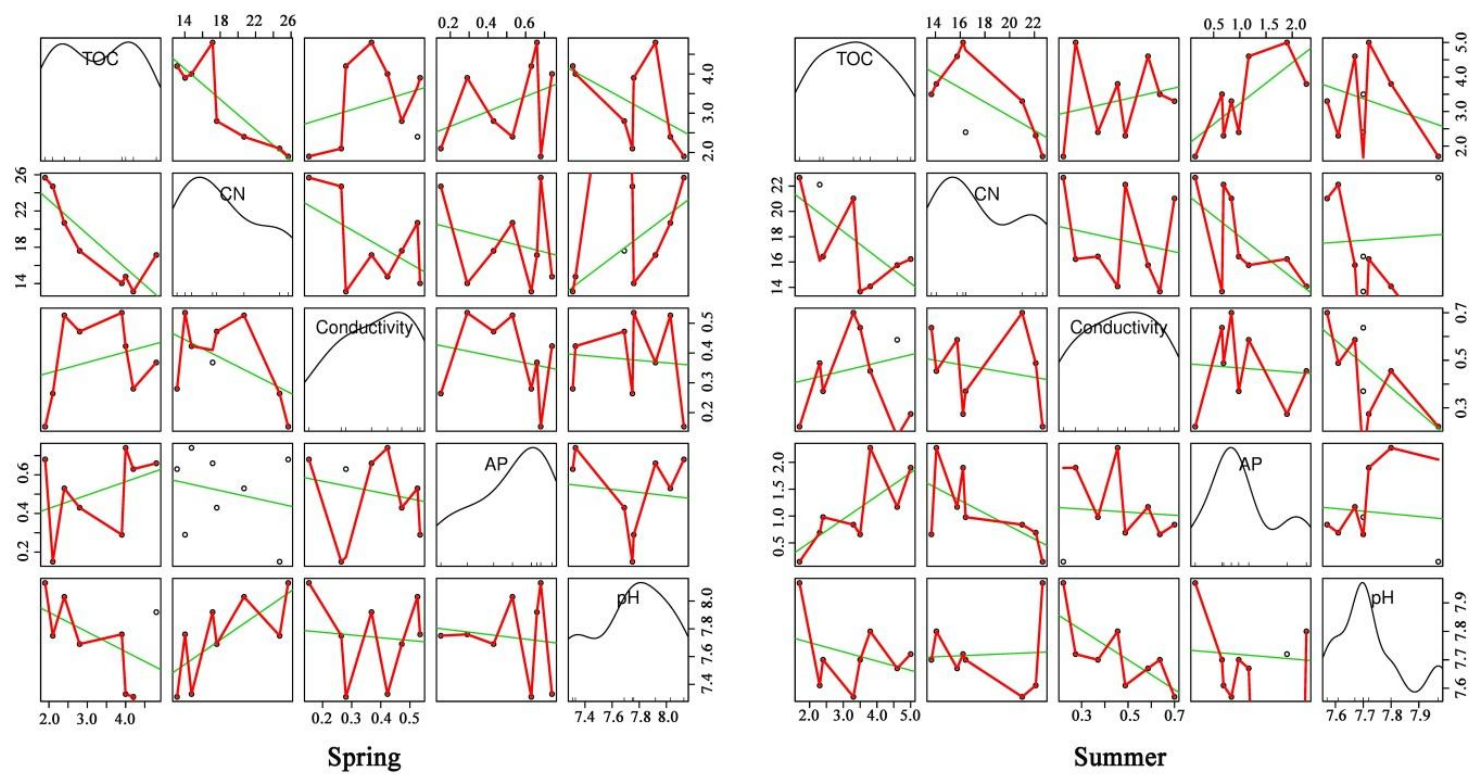

Figure 2. Correlations between environmental variables in surface sediments in spring and summer. Diagonal line denotes the histogram of environmental variables in eight sampling sites; red dashed line denotes the movement locus of scatter points corresponding to eight sampling sites; green line denotes the fitting curve of two variables.

\section{Response of diatom assemblages to environmental variables}

The dominant diatom species in surface sediments exhibits the disparities in different sampling sites (Fig. 3), with the benthic taxa being dominant, such as Cymbella, Navicula, Gomphonema and Fragilaria. The planktonic taxa, such as Cyclotella meneghiniana and Actinocyclus, account for a relatively large proportion 
of diatoms' total abundance in the sampling sites like SCD and YZZ. DCA ordination of surface sediments indicates that the genus Gomphonema prevails in the middle part of sampling sites, while diatom assemblages are dominated by the genus Cymbella for the southward sampling sites (Fig.4). The first axis of the DCA ordination explains $23.1 \%$ of the variation in the diatom distribution. Six environmental variables (water level, TOC, $\mathrm{C} / \mathrm{N}, \mathrm{AP}, \mathrm{pH}$, conductivity) jointly explain $51.2 \%$ of the variation of the diatom assemblages based on the RDA ordination. Redundant variables with higher values of the inflation factor $(>10)$ are not accounted for in the further analysis. Water level, TOC and $\mathrm{pH}$ finally constitute the environmental group to explain the variance of the diatom distribution in surface sediments. RDA with one constrained axis indicates that $\mathrm{pH}$, water level and TOC account for $13.1 \%$, $9.7 \%$ and $8.8 \%$ of species variance respectively.

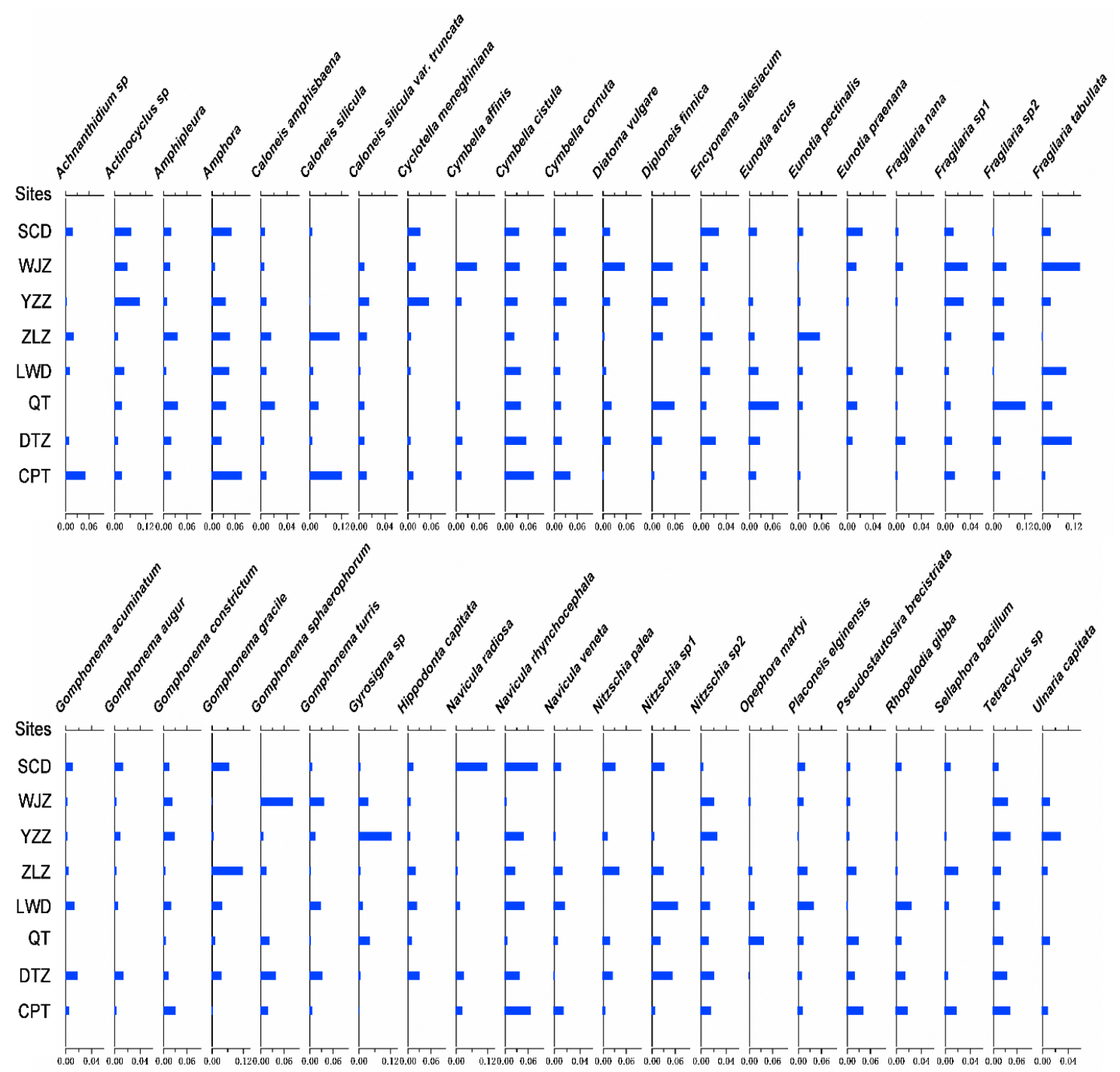

Figure 3. Distribution of 42 diatom taxa in surface sediments. Abundance of diatom taxa in one sample is at least more than $1 \%$. 


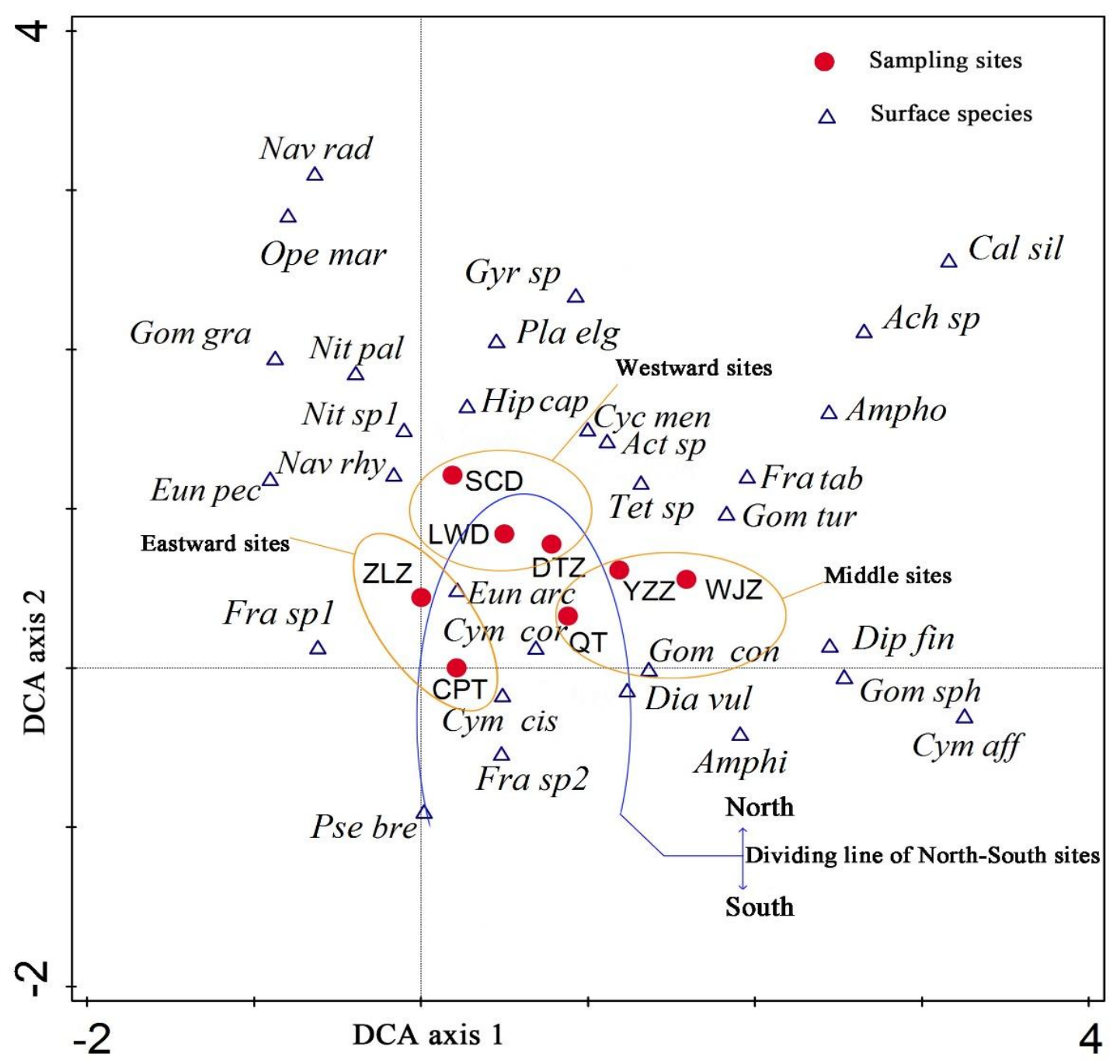

Figure 4. DCA ordination of diatom assemblages in surface sediments. Abbreviation of the selected diatom species: Nav rad = Navicula radiosa; Ope mar = Opephora martyi; Cal sil = Caloneis silicula; Gyr sp = Gyrosigma sp; Ach sp = Achnanthidium sp; Pla elg = Placoneis elginensis; Gom gra = Gomphonema gracile; Nit pal = Nitzschia palea; Hip cap = Hippodonta capitata; Ampho = Amphora : Nit spl = Nitzschia sp1; Cyc men = Cyclotella meneghiniana; Act $s p=$ Actinocyclus sp; Nav rhy = Navicula rhynchocephala $;$ Fra tab = Fragilaria tabullata; Eun pec $=$ Eunotia pectinalis; Tet $s p=$ Tetracyclus $s p ;$ Gom tur $=$ Gomphonema turris $;$ Eun arc = Eunotia arcus; Fra spl = Fragilaria sp1; Cym cor $=$ Cymbella cornuta $;$ Dip fin $=$

Diploneis finnica; Gom con = Gomphonema constrictum; Gom sph = Gomphonema sphaerophorum; Dia vul = Diatoma vulgare; Cym cis = Cymbella cistula $;$ Cym aff = Cymbella affinis; Amphi = Amphipleura; Fra sp2 = Fragilaria sp2; Pse bre $=$ Pseudostautosira brecistriata.

The distribution of environmental variables in the sediment core has been introduced in the study of Guo et al. (2012). Three selected environmental variables, TOC, $\mathrm{pH}$, and water level, explain $12.5 \%$ of the total variance of the diatom assemblages in the sediment core. The explained variability by environmental variables in the sediment core is smaller than that in surface sediments, since the number of diatom taxa with a zero value in the sediment core is larger, contributing to the relatively poor performance of spe- 
cies transformation. Water level, $\mathrm{pH}$ and TOC independently capture $6.4 \%, 5.9 \%, 2.4 \%$ of the variance of the diatom assemblages in the sediment core respectively. The inflation factor of water level is smaller than those of other two variables, implying that water level is less affected by the collinear effect and more independently accounts for the distribution of diatom assemblages. In addition, the second axis of RDA ordination clearly divides the sediment core into two parts along the water level gradient (Fig.5).

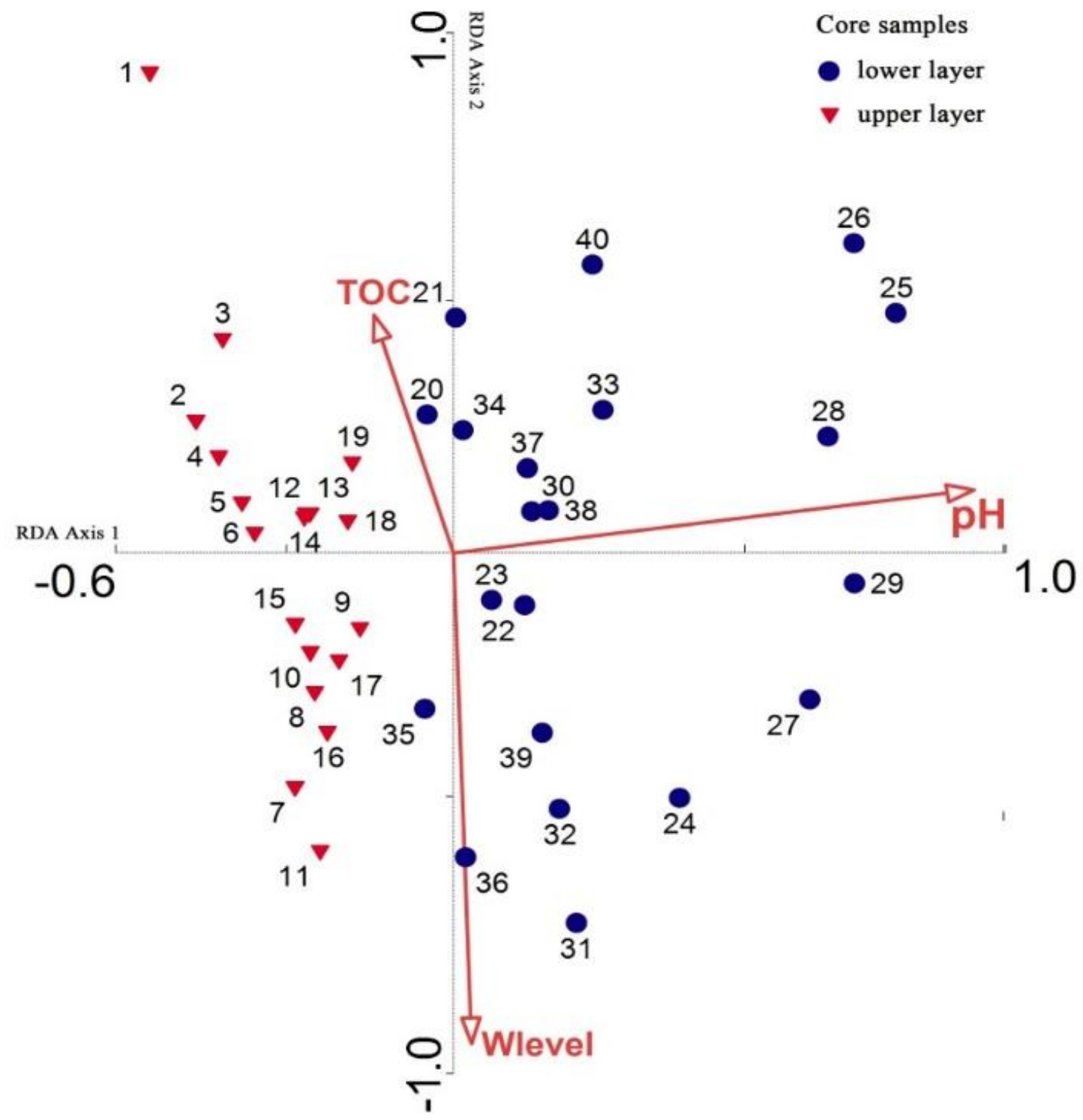

Figure 5. RDA ordination showing the relation between sample scores and the selected environmental variables in the sediment core

\section{Spatio-temporal response of diatom assemblages to water level}

Thirty-four diatom species are simultaneously found in surface sediments and in the sediment core (Fig. A2). Twenty-five diatom species satisfy the principle of ordination. As shown in Table 2, water level has a closer relation with the distribution of diatom 
assemblages in the lower layer of the sediment core. Water level accounts for more variability of diatom data in the sediment core compared with surface sediments based on the eigenvalues of the first two axes. The impact of water level on the richness and evenness of diatom species is not significant with respect to surface sediments and the upper layer of the sediment core, but this impact shifts in the lower layer of the sediment core (Fig.6). In addition, the distribution of diatom species seems more dispersed in surface sediments and in the upper layer of the sediment core, which may be attributed to the spatial isolation of diatom species and the impact of human disturbance on the sediments. The planktonic taxa, such as Cyclotella meneghiniana and Actinocyclus sp, closely correlate with water level. In contrast, diatom species, such as Cymbella cistula and Amphora, show a relatively weak relation with water level. This relation experiences a shift for the diatom taxa, such as Navicula radiosa, Navicula rhynchocephala and Nitzschia palea, with respect to three sediment scenarios.

Table 2. RDA ordination on surface sediments, the upper layer and the lower layer of the sediment core

\begin{tabular}{cccc}
\hline Scenario & Surface & Upper & Lower \\
Index & 0.156 & 0.327 & 0.366 \\
Eigenvalue (First axis) & 0.213 & 0.303 & 0.278 \\
Eigenvalue (Second axis) & 1.1 & 2.4 & 8.5 \\
Pseudo-F & 0.344 & 0.046 & 0.004 \\
P & &
\end{tabular}
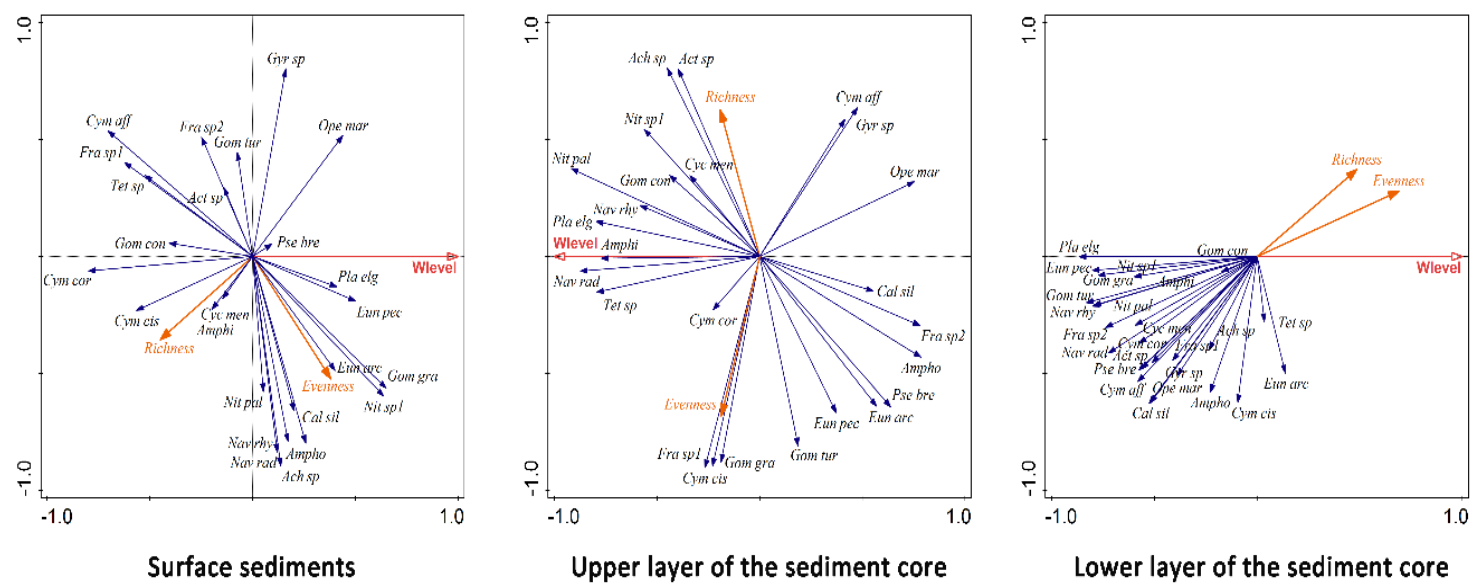

Figure 6. Response of diatom assemblages to water level in three sediment scenarios. Abbreviation of diatom taxa has been demonstrated in Fig. 4.

\section{Discussion}

Lake sediment, as a supporter registering environmental changes, can provide us with high resolution records of variations in temporal and spatial scales. The multiproxies analysis of sediments improves our knowledge of the correlation between environmental variables and aquatic plants. The investigation of surface sediments 
shows the seasonal effects of sediment property in Lake Baiyangdian. The results of the ordination indicate that water level largely account for the distribution of diatom assemblages in surface sediments and in the sediment core. Spatial isolation and human activities affect the microhabitat of diatoms in the lake system, thereby altering the diversity of diatoms and the response of the diatom assemblages to water level. Assessing the spatio-temporal feature of water level and its impact on the distribution of diatom assemblages in a single lake can improve our knowledge of environmental changes in the specific lacustrine ecosystem, in comparison with the studies using a group of lakes.

\section{Seasonal effects of surface sediments}

The composition of grain size does not show the significantly seasonal effects in Lake Baiyangdian since sand is an essential component accounting for the variations of grain size. Clay and silt content in winter reached its maximum for the entire year. Water flow slowed down to a standstill and human disturbance on the body of water is weak during the frozen period. In contrast, the silt contents in spring and summer are higher since the body of water may experience a strong turbidity as a result of the ice melting and frequent rainfalls. Silt content is typically used to describe the flow intensity and turbidity of the medium (Schmieder et al., 2004). In addition, the distribution of grain size in each season matches the topography of the water table in the lake and potentially indicates the direction of water flow.

Water level has a significant seasonal effect but is weakly related to the composition of grain size, which is contrary to the findings of Dusini et al. (2009) that grain size and water level were closely correlated in shallow lakes. Water level, as a static variable, sometimes does not promptly response to the variations of the flow intensity. Namely higher water levels may not equate with stronger hydrodynamics. Bachmann et al. (2000) proposed a concept of dynamic lake parameters based on the lake area and water depth. The deposition of surface sediments may be driven by wind and wave in case the dynamic lake parameter is more than 0.8 . The dynamic parameters of the lake in spring and summer are larger than this value, implying that the seasonal wind and wave movements may determine the water-level fluctuation and the hydrodynamic of the lake.

Lake productivity reflected by the variable TOC shows the significant seasonal effects with the vigorous growth of aquatic plants. This result could be further demonstrated via the higher concentration of available phosphorus in summer. However the value of TOC in winter is relatively low, implying that aquatic plants are weakly active in this season. This result is in line with the findings that organic matter content within surface sediments in shallow lakes is higher in summer owing to the growth of phytoplankton (Yu et al., 2009).

\section{Response of diatom assemblages to water level}

Lake Baiyangdian has no definite shallow-to-deep water transects. The water level disparity in modern times is depicted alternatively in a way of spatial distribution. In addition, the spatio-temporal impact of water level on diatom assemblages is implemented in a unique lake, which is different from traditional studies examining the correlation between environmental variables and diatom assemblages based on a group of lakes (Hassan et al., 2009; Yang et al., 2008; Werner and 
Smol, 2005). An integration homogenizes the environmental differences between lakes and may conceal the peculiar interactions between aquatic plants and environmental variables in each lake. Higher water levels increase the abundance of planktonic taxa, e.g. Cyclotella and Actinocyclus, while benthic types, e.g. Nitzschia and Cymbella, generally dominate in a shallower water level. This finding is similar with that in other shallow lakes (Shinneman et al., 2010; Laird and Cumming, 2008).

It is found that $\mathrm{pH}$, water level and AP largely account for the distribution of diatom assemblages in surface sediments. Li et al. (2010) found that $\mathrm{pH}$ and total phosphorus were the determining variables affecting the distribution of diatom assemblages in the body of water in Lake Baiyangdian. Further the diatom taxa living in the body of water are similar to that found in surface sediments, implying that the interactions between the body of water and surface sediments homogenize the response of diatom assemblages to environmental variables.

The spatio-temporal fluctuations of water level affect the distribution of diatom assemblages in Lake Baiyangdian. On one hand, the spatial partition facilitates the occurrence of new diatom species and species adaption to diverse habitats. On the other hand, the construction of hydraulic projects in the upper reach significantly shifts the hydrodynamics of the lake, thereby potentially altering the interspecific relation between diatom species and the response of diatom assemblage to water level. The impact of human disturbance on the response of diatom assemblages to hydrological processes varies in different spatial scales (Donohue et al., 2010). We explicitly aim at one dimension of human impact, namely the construction of hydraulic projects leading to the changes in water dynamics of the shallow lake. However, we are well aware that another aspect of human impact on the lake ecosystem (eutrophication) also plays an important role in the composition of diatom assemblages, which is not accounted for in this study.

The quantitative analysis of the response indicates that spatial isolation promotes a closer relation of $60 \%$ diatom species with water level, comparing the surface sediments with the upper layer of the sediment core (Table 3). Human disturbance accounts for $40 \%$ enhancive correlations between water level and diatom species, comparing the upper layer with the lower layer of the sediment core. The richness and evenness indices of diatom assemblage relate more closely to water level with respect to the lower layer of the sediment core, implying that spatial isolation (surface sediments) and diverse hydrodynamics (the upper layer of the sediment core) weaken the response of the whole diatom community to water level. Grey correlation analysis can reveal the quantitative relation between diatom species and water level, but may lose some ecological information since this method uniquely concentrates on one environmental variable. We might obtain more using less quantitative but more ecologically meaningful approach (Rioual et al., 2002). Defining an unambiguous breakpoint to differentiate the degree of human disturbance in shallow lakes is also a tough question. This study proposes a criterion of human disturbance on the lacustrine system based on the specific hydrological condition of the lake. The futural expectation is to interpret the data more securely integrating more biotic variables. 
Table 3. Correlational coefficient between diatom distribution and water level for surface sediments, upper and lower layer of sediment core. Abbreviation of diatom species refers to Fig. 4.

\begin{tabular}{|c|c|c|c|c|c|c|c|}
\hline & & \multicolumn{2}{|c|}{ Surface sediments } & \multicolumn{2}{|c|}{ Core (upper layer) } & \multicolumn{2}{|c|}{ Core (lower layer) } \\
\hline & & mean & SD & mean & SD & mean & SD \\
\hline \multirow{25}{*}{ Species } & Fra sp2 & 0.756 & 0.038 & 0.802 & 0.025 & 0.613 & 0.068 \\
\hline & Eun arc & 0.604 & 0.057 & 0.578 & 0.057 & 0.660 & 0.059 \\
\hline & Act $s p$ & 0.687 & 0.046 & 0.583 & 0.066 & 0.677 & 0.061 \\
\hline & Cal sil & 0.676 & 0.051 & 0.632 & 0.057 & 0.597 & 0.069 \\
\hline & Nit spl & 0.590 & 0.063 & 0.662 & 0.051 & 0.666 & 0.060 \\
\hline & Eun pec & 0.667 & 0.059 & 0.628 & 0.054 & 0.648 & 0.057 \\
\hline & Cym aff & 0.635 & 0.054 & 0.621 & 0.061 & 0.607 & 0.064 \\
\hline & Ampho & 0.702 & 0.054 & 0.595 & 0.062 & 0.685 & 0.056 \\
\hline & Pse bre & 0.710 & 0.043 & 0.566 & 0.064 & 0.677 & 0.055 \\
\hline & Cym cis & 0.699 & 0.044 & 0.643 & 0.053 & 0.709 & 0.056 \\
\hline & Gom tur & 0.693 & 0.047 & 0.552 & 0.057 & 0.658 & 0.063 \\
\hline & Ope mar & 0.509 & 0.066 & 0.691 & 0.042 & 0.553 & 0.074 \\
\hline & Nav rad & 0.603 & 0.057 & 0.662 & 0.054 & 0.577 & 0.068 \\
\hline & Fra spl & 0.632 & 0.056 & 0.637 & 0.054 & 0.585 & 0.069 \\
\hline & Cyc men & 0.762 & 0.034 & 0.582 & 0.062 & 0.666 & 0.062 \\
\hline & Tet $s p$ & 0.587 & 0.057 & 0.708 & 0.048 & 0.657 & 0.064 \\
\hline & Nit pal & 0.702 & 0.056 & 0.632 & 0.054 & 0.673 & 0.058 \\
\hline & Cym cor & 0.669 & 0.046 & 0.616 & 0.066 & 0.705 & 0.057 \\
\hline & Gom gra & 0.685 & 0.050 & 0.739 & 0.044 & 0.662 & 0.058 \\
\hline & Gyr sp & 0.591 & 0.065 & 0.733 & 0.035 & 0.595 & 0.066 \\
\hline & Amphi & 0.686 & 0.051 & 0.693 & 0.058 & 0.614 & 0.068 \\
\hline & Pla elg & 0.605 & 0.067 & 0.569 & 0.055 & 0.599 & 0.071 \\
\hline & Nav rhy & 0.610 & 0.054 & 0.593 & 0.055 & 0.596 & 0.067 \\
\hline & Gom con & 0.590 & 0.062 & 0.643 & 0.059 & 0.729 & 0.054 \\
\hline & Ach sp & 0.648 & 0.054 & 0.521 & 0.068 & 0.636 & 0.063 \\
\hline \multirow{2}{*}{ Assemblage } & Richness & 0.620 & 0.054 & 0.758 & 0.031 & 0.644 & 0.063 \\
\hline & Evenness & 0.584 & 0.056 & 0.905 & 0.011 & 0.578 & 0.066 \\
\hline
\end{tabular}

\section{Conclusion}

This study assesses the spatio-temporal response of the diatom assemblages to water level fluctuations based on the sedimentary biotic and abiotic variables. Accounting for this response using the historical records allows us to better understand the impact of human activities on lake ecosystems. Therefore, approaches to quantify the relationship between aquatic species and environmental variables deserve further attention, in order to preserve the biodiversity and assess environmental changes in the shallow lakes. A promising way is to investigate the diatom communities in lake water and construct the relation with the sedimentary diatom assemblages.

Acknowledgements. This work was supported by National Natural Science Foundation of China (51179007), Beijing Natural Science Foundation (8132039), National Science and Technology Support Program (2011BAC09B07), and the Fundamental Research Funds for the Central Universities. We thank two anonymous reviewers for very constructive feedback on the submitted manuscript. 


\section{REFERENCES}

[1] Alagarsamy, R. (2006): Distribution and seasonal variation of trace metals in surface sediments of the Mandovi estuary, west coast of India. - Estuarine, Coastal and Shelf Science 67: 333-339.

[2] Bachmann R. W., Hoyer M. V., Canfield D. E. (2000): The potential for wave disturbance in shallow Florida Lakes. - Lake and Reservoir Management 16: 281-291.

[3] Battarbee R. W. (2000): Palaeolimnological approaches to climate change, with special regard to the biological record. - Quaternary Science Reviews 19: 107-124.

[4] Ter Braak C. J. F. and Smilauer P. (2002): CANOCO reference manual and user's guide to Canoco for Windows - software for canonical community ordination (version 4.5). Microcomputer Power Press Publishing, Ithaca.

[5] Chen H., Ma L. K., Guo W., Yang Y., Guo T., Feng C. (2013): Linking water quality and quantity in environmental flow assessment in deteriorated ecosystems: A food web view. PLOS ONE 8.

[6] DePinto J. V., Young T. C., Martin S. C. (1981): Algal-available phosphorus in suspended sediments from lower Great Lakes tributaries. - Journal of Great Lakes Research 7: 311325 .

[7] Donohue I., Leira M., Hobbs W., Leon V. L., O’Reilly J., Irvine K. (2010): Rapid ecosystem recovery from diffuse pollution after the Great Irish Famine. - Ecological Applications 20: 1733-1743.

[8] Dusini D. S., Foster D. L., Shore J. A., Merry C. (2009): The effect of Lake Erie water level variations on sediment resuspension. - Journal of Great Lakes Research 5: 1-12.

[9] Facca C., Sfriso A., Socal G. (2005): Temporal and spatial distribution of diatoms in the surface sediments of the Venice Lagoon. - Botanica Marina 45: 170-183.

[10] Freeland J., Richardson J., Foss L. (1999): Soil indicators of agricultural impacts on northern prairie wetlands: Cottonwood lake research area, North Dakota, USA. Wetlands 19: 56-64.

[11] Fu C., Zheng J., Zhao J., Xu W. (2001): Application of grey relational analysis for corrosion failure of oil tubes. - Corrosion Science 43: 881-889.

[12] Guo T., Yang Z. F., Chen H. (2012) Pollen assemblages and their environmental correlates during the past 200 years inferred from sediments records in a shallow lake. Procedia Environmental Sciences 13: 363-376.

[13] Habib O. A., Tippett R., Murphy K. J. (1997): Seasonal changes in phytoplankton community structure in relation to physico-chemical factors in Loch Lomond, Scotland. Hydrobiologia 350: 63-79.

[14] Hassan G. S., Tietze E., De Francesco C. G. (2009): Modern diatom assemblages in surface sediments from shallow lakes and streams in southern Pampas (Argentina). Aquatic Sciences 71: 487-499.

[15] Heinsalu A., Luup H., Alliksaar T., Nõges P., Nõges T. (2008): Water level changes in a large shallow lake as reflected by the plankton: periphyto-ratio of sedimentary diatoms. Hydrobiologia 599: 23-30.

[16] Huang C. C., Pang J. L., Zhou Q. Y., Chen S. E. (2004): Holocene pedogenic change and the emergence and decline of rain-fed cereal agriculture on the Chinese Loess Plateau. Quaternary Science Reviews 23: 2525-2535.

[17] Juggins S. (2003): C2 Software for ecological and palaeoecological data analysis and visualization (version 1.5). - Newcastle University Publishing, UK.

[18] Keeney D. R., Konrad J. G., Chesters G. (1970): Nitrogen distribution in some Wisconsin Lake Sediments. - Water Pollution Control Federation 42: 411-417.

[19] Kingsbury M. Laird V. K. R., Cumming B. F. (2012): Consistent patterns in diatom assemblages and diversity measures across water-depth gradients from eight Boreal lakes from north-western Ontario (Canada). - Freshwater Biology 57: 1151-1165.

[20] Koren N. and Klein M. (2000): Rate of sedimentation in Lake Kinneret, Israel: spatial 
and temporal variations. - Earth Surface Processes and Landforms 25: 895-904.

[21] Laird K. R. and Cumming B. F. (2008): Reconstruction of Holocene lake level from diatoms, chrysophytes and organic matter in a drainage lake from the Experimental Lakes Area (northwestern Ontario, Canada). - Quaternary Research 69: 292-305.

[22] Leeben A., Freiberg R., Tõnno I., Kõiv T., Alliksaar T., Heinsalu A. (2013): A comparison of the Paleolimnology of Peipsi and Võrtsjarv: connected shallow lakes in north-eastern Europe for the twentieth century, especially in relation to eutrophication progression and water-level fluctuations. - Hydrobiologia 710: 227-240.

[23] Li J. Y., Qi Y. Z. (2010): The freshwater algae of China - Naviculaceae (Volume 14). Science Press Publishing, Beijing.

[24] Li Y. M., Zhao Q., Feng G. P., Liu H. P., Wang Y. F. (2010): The diatom assemblages and their response to different environments of Baiyangdian Lake, China. - Acta Ecologica Sinic 30: 4559-4570.

[25] Liu Q., Yang X. D., Anderson N. J., Liu E. F., Dong X. H. (2012): Diatom ecological response to altered hydrological forcing of a shallow lake on the Yangtze floodplain, SE China. - Ecohydrology 5: 316-325.

[26] Moos M. T., Laird K. R., Cumming B. F. (2005): Diatom assemblages and water depth in Lake 239 (Experimental Lakes Area, Ontario): implications for paleoclimatic studies. Journal of Paleolimnology 34: 217-227.

[27] Mucha A. P., Vasconcelos M. T., Bordalo A. A. (2003): Macrobenthic community in the Douro estuary: relations with trace metals and natural sediment characteristics. Environmental Pollution 121: 169-180.

[28] Nguetsop V. F., Servant V. S., Servant M., Roux M. (2010): Long and short-time scale climatic variability in the last 5500 years in Africa according to modern and fossil diatoms from Lake Ossa (Western Cameroon). - Global and Planetary Change 72: 356367.

[29] Phiri C., Day J., Chimbari M., Dhlomo E. (2007): Epiphytic diatoms associated with a submerged macrophyte, Vallisneria aethiopica, in the shallow marginal areas of Sanyati Basin (Lake Kariba): a preliminary assessment of their use as biomonitoring tools. Aquatic Ecology 41: 169-181.

[30] Puusepp L. and Punning J. M. (2011): Spatio-temporal variability of diatom assemblages in surface sediments of Lake Peipsi. - Journal of Great Lakes Research 37: 33-40.

[31] Qi Y.Z. (1995): The freshwater algae of China - Centricae (Volume 4). - Science Press Publishing, Beijing.

[32] Qi Y. Z. (2004): The freshwater algae of China - Pennatae (Volume 10). - Science Press Publishing, Beijing.

[33] Rioual P., Andrieu-Ponel V., Rietti-Shati M., Battarbee R. W., de Beaulieu J. L., Cheddadi R., Reille M., Svobodova H., Shemesh A. (2001): High-resolution record of climate stability in France during the last interglacial period. - Nature 413: 293-296.

[34] Schmieder K., Schunemann B., Schroder H. G. (2004): Spatial patterns of surface sediment variables in the littoral zone of Lake Constance (Germany). - Archiv Fur Hydrobiologie 161: 455-468.

[35] Shi Z. X. (2004): The freshwater algae of China - Gomphonemaceae (Volume 12). - Science Press Publishing, Beijing.

[36] Shinneman A. L. C., Bennett D. M., Fritz S. C., Schmieder J., Engstrom D. R., Efting A., Holz J. (2010): Inferring lake depth using diatom assemblages in the shallow, seasonally variable lakes of the Nebraska Sand Hills (USA): Calibration, validation, and application of a 69-lake training set. - Journal of Paleolimnology 44: 443-464.

[37] Stacklies W., Redestig H., Scholz M., Walther D., Selbig J. (2007): pcaMethods - a bioconductor package providing PCA methods for incomplete data. - Bioinformatics 23: 1164-1167.

[38] Tammeorg O., Niemistö J., Horppila J., Haldna M., Kangur K. (2013): Sedimentation and resuspension dynamics in Lake Vesijärvi (Finland): comparison of temporal and spatial 
variations of sediment fluxes in deep and shallow areas. - Fundamental and Applied Limnology 182: 297-307.

[39] Velghe K., Vermaire J. C., Gregory-Eaves I. (2012) Declines in littoral species richness across both spatial and temporal nutrient gradients: a palaeolimnological study of two taxonomic groups. - Freshwater Biology 57: 2378-2389.

[40] Viguri J., Verde J., Irabien A. (2002): Environmental assessment of polycyclic aromatic hydrocarbons (PAHs) in surface sediments of the Santander Bay, Northern Spain. Chemosphere 48: 157-165.

[41] Wang Q., Yang X. D., Hamilton P. B., Zhang E. L. (2012): Linking spatial distribution of sediment diatom assemblages with hydrological depth profiles in a plateau deep-water lake system of subtropical China. - Fottea 12: 59-73.

[42] Weilhoefer C.L. and Pan Y. D. (2006): Diatom-based bioassessment in wetlands: How many samples do we need to characterize the diatom assemblages in a wetland adequately. - Wetlands 26: 793-802.

[43] Werner P. and Smol J. P. (2005): Diatom-environmental relationships and nutrient transfer functions from contrasting shallow and deep limestone lakes in Ontario, Canada. Hydrobiologia 533: 145-173.

[44] Witkowski A., Cedro B., Kierzek A., Baranowski D. (2009): Diatoms as a proxy in reconstructing the Holocene environmental changes in the south-western Baltic Sea: the lower Rega River Valley sedimentary record. - Hydrobiologia 631:155-172.

[45] Xie D., Yu D., You W. H., Wang L. G. (2013): Algae mediate submerged macrophyte response to nutrient and dissolved inorganic carbon loading: A mesocosm study on different species. - Chemosphere 93:1301-1308.

[46] Yang X. D., Anderson N. J., Dong X. H., Shen J. (2008): Surface sediment diatom assemblages and epilimnetic total phosphorus in large, shallow lakes of the Yangtze floodplain: their relationships and implications for assessing long-term eutrophication. Freshwater Biology 53: 1273-1290.

[47] Yu H. Q., Wang J. C., Deng J. T., Ao H. Y., Fang T. (2009): Effect of dredging and reestablishment of aquatic macrophytes on organic matter in sediments of west Wuli $\mathrm{Hu}$ of Taihu. - Journal of Agro-Environmental Science 28: 1903-1907.

[48] Zhang L. L., Liu J. L., Yang Z. F., Li Y., Yang Y. (2013): Integrated ecosystem health assessment of a macrophyte-dominated lake. - Ecological Modelling 252:141-152.

\section{APPENDIX}

We investigated the diatom assemblages in the sediment core and reconstructed the water levels based on the indicative diatom species (Chen et al., 2013).

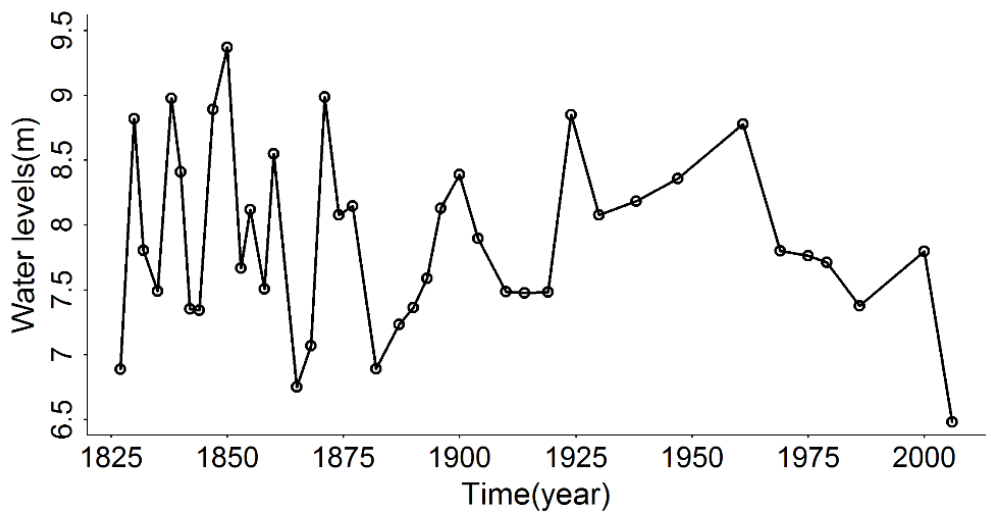

Figure A1. Water levels in the Lake Baiyangdian from 1827 to 2008 
Thirty-four diatom species are simultaneously found in surface sediments and in the sediment core. Here we show the distribution of these co-occurred diatom species in the sediment core.

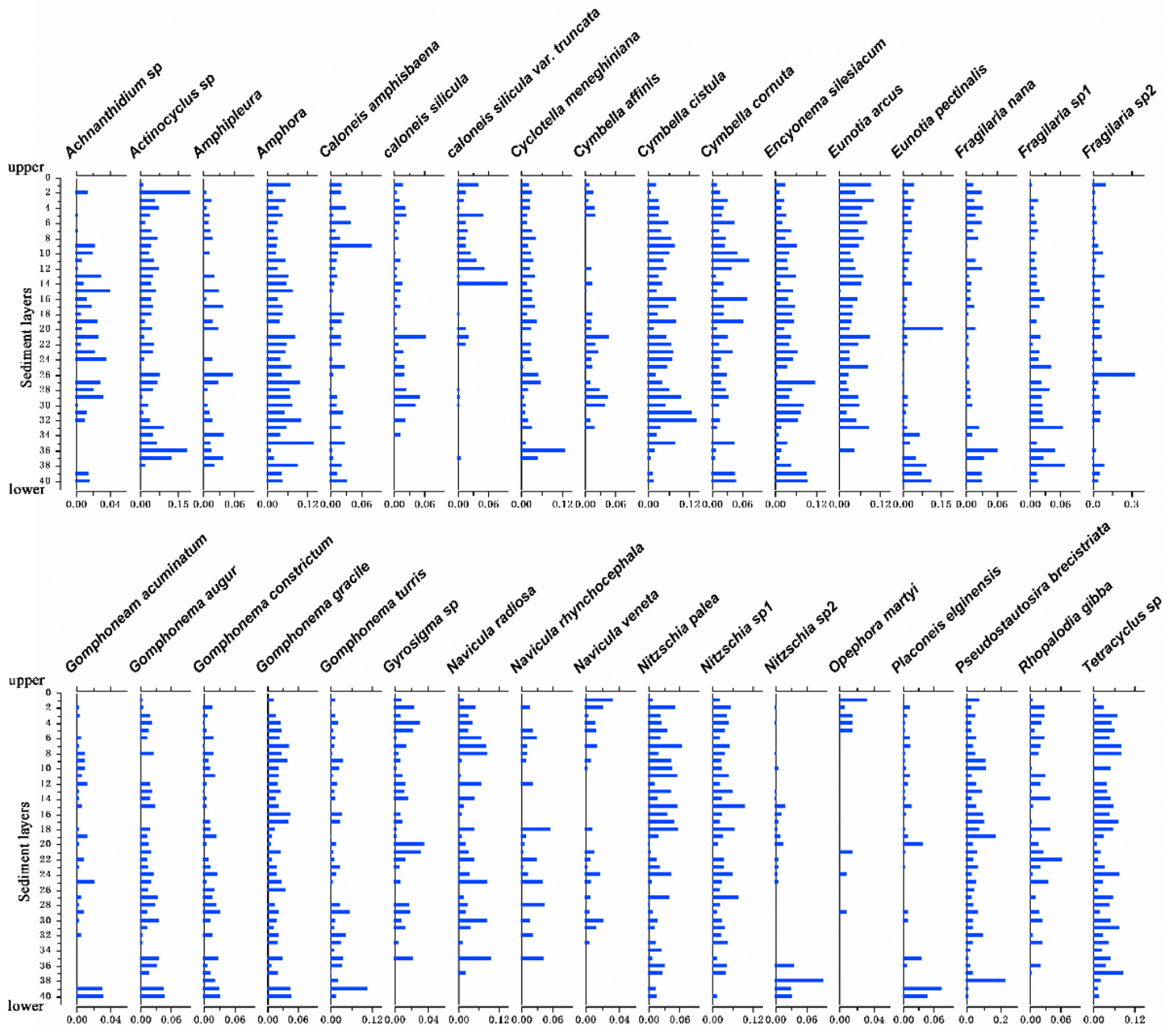

Figure A2. The distribution of the co-occurred diatom species in the sediment core 